\title{
INFORMAÇÃO, TRABALHO E DINHEIRO: A FELICIDADE ESTÁ EM SE FAZER O QUE SE GOSTA
}

Barbara Coelho Neves - barbara.coelho@defensoria.ba.gov.br Doutoranda em Educação pela Universidade Federal da Bahia (UFBA).

Docente Universidade Federal de Sergipe (UFS).

HIMANEN, Pekka. La ética del hacker y el espíritu de la era de la información. Barcelona: Destino, 2003.

"Trabajamos para trabajar y vivimos para vivir". Himanen.

A abordagem do livro é teórica. O autor nutre a intenção de apresentar os valores que fundamentam a ética hacker, com enfoque na ética protestante e o espírito do capitalismo de Max Weber. Pekka Himanen se apropria da obra weberiana com o intuito de utilizá-la como contraponto para descrever os sete valores da ética hacker.

Alusão com a obra de Max Weber, $A$ ética protestante e o espírito do capitalismo. Enquanto Weber coloca os fundamentos da burocracia como bases da ética do trabalho, o Himanen chamará atenção que na atual sociedade a expertise, a criatividade e o amor pela liberdade são os fundamentos de uma nova ética que é muito mais representativa e se materializa com muito mais força na imaterialidade da internet.

$\mathrm{Na}$ cultura hacker, a ética do trabalho ganha novos contornos, deixando de lado a moral batizada na rotina, na prestação de resultados e na produção de valor associado, exclusivamente, ao dinheiro.

\section{BLOCO DO RESUMO CRÍTICO}

O raciocínio é coerente. Trata-se de uma leitura que flui, facilitando o entendimento. Porém, vale salientar que a edição que realizei a leitura mais apurada 
e resenha foi a tradução espanhola da edição original The hacker ethic and the spirit of the information age. Nova York: Random House, 2001. HIMANEN, Pekka, TORVALDS, Linus (“Prólogo") e CASTELLS, Manuel (“Epílogo”). A edição espanhola continha alguns pequenos erros de grafia no idioma, o que ocasionou algumas interrupções. Outro ponto que também vale a ressalva é a ausência de elementos bibliográficos para situar a edição em questão. A tradução em português do original já possui uma recensão elaborada por Mocelin ${ }^{1}$. Entretanto, a tradução espanhola, assim como a tradução em português, traz elementos diferentes, a exemplo dos títulos atribuídos às seções. Ao observar as três obras, percebi que os enunciados e as palavras atribuídas podem levar a compreensão diferente de algumas partes do conteúdo. Ao fazer essa comparação é observável que a tradução espanhola está mais fiel ao original publicado em inglês em 2001 que a publicada em português em 2003.

O argumento central do livro são os valores da ética hacker para uma nova perspectiva de trabalho que vai além dessa atividade em si mesma. Para tanto, o leque de exemplos são muitos. Percebe-se que este recurso somado às questões efetuadas de maneira implícita ao longo de cada capítulo, repercute no processo de compreensão com cunho explicativo, enriquecendo o texto.

As principais virtudes do texto constituem a ampla revisão de conceitos e definições que o autor apresenta a partir dos valores da ética hacker sempre em contraponto com a ética protestante. Os valores são sempre apontados em sua origem, com riqueza de exemplos. Outra virtude do texto é a contraposição de visões das duas abordagens sobre o objeto discutido "ética". O método de exposição é didático, o que facilita a leitura mesmo para aqueles que não leram a obra citada do Weber ou não conhecem os termos do tema "cultura hacker".

Quanto à perspectiva teórica do autor, Weber norteia o coração do livro, onde são apresentados os pressupostos sugeridos para a ética hacker, claro que sob uma perspectiva contrária. Outras ideias e autores que também circulam o texto são (hacker na sociedade informacional) Manoel Castells e (software livre) Linus Torwads.

\footnotetext{
${ }^{1}$ Publicou resenha do original em inglês em 2008, disponível em: http://www.scielo.br/pdf/soc/n19/a15n19.pdf.
} 
BLOCO DOS ARGUMENTOS: a obra e os aspectos observados

A demonstração de argumentos do autor, Pekka Himanen, fica por conta das evidências por meio de exemplos e dos autores elencados nas diferentes partes conceituais que compõem o texto.

O livro está dividido em três grandes partes mais sua conclusão. Cada uma dessas partes apresenta subdivisões capituladas. Contudo, gostaria de chamar atenção para o prefácio escrito por Manuel Castells e pelo prólogo de Linus Torwalds. Ambos participaram de pesquisas com o autor sobre temas correlatos em diversos países.

No prefácio, Castells começa falando da origem da denominação hacker no MIT (Massachusetts Institute of Technology), na década de 1960, para os programadores mais apaixonados do Vale do Silício. Castells de cara já anuncia a conotação criminalista e discriminatória atribuída pela mídia aos hackers, em meados de 1980. Foi a partir dessa parte que parti para uma reflexão, talvez demasiado "templano", de que é importante a distinção entre hacker e cracker. Embora que, há pouco tempo em conversa com um hacker especialista em segurança da informação este tenha informado que não importava essa diferenciação. Segundo esse especialista, "tantos aqueles que entravam em sistemas para mostrar suas falhas, quanto aqueles que atacam são considerados hackers. Após a leitura que fiz desse livro comecei a perceber que este argumento do especialista se adéqua, exatamente àqueles que Castells chamou de crackers e que é importante sim fazer as distinções com relação às ações e ao comportamento de ambos.

Logo em seguida Linus Torwalds - inventor do sistema operacional Linux inicia seu prólogo com um questionamento "por que o hacker é como é?". Ele vai responder com o apoio da Lei de Linus:

La ley de linus establece que todas nuestras motivaciones se pueden agrupar en tres categorías básicas. Y lo que es aún más importante, el progreso consiste en ir pasando de una categoría a la siguiente como $<<f a s e s>>$ de un proceso de evolución. Las categorias son, por este orden, $<<$ supervivencia $>>$, <<vida social $>>$ y $<<$ entretenimiento $>>$. (p. 9).

Torwalds vai dizer que acredita que os hackers se interessaram tanto pelo Linux por razões de semelhanças de princípios e valores. As categorias da Lei de 
Linus são elementos básicos da motivação dos hackers, mas não são suficientes para eles (supervivência, vida social e entretenimento). Ou seja, para um hacker o computador extrapola sua utilização para a sobrevivência, pois ele o utiliza para seus vínculos sociais e entretenimento.

Himanen inicia sua discussão introduzindo o leitor com a "Ética hacker do trabalho". Esse capítulo fará uma associação, ou melhor, uma espécie de contraponto, com a ética protestante weberiana. Ele vai concordar com Torwalds que o hacker compreende o computador como entretenimento "em si", logo programa porque a ação de programar lhe é extremamente prazerosa e interessante. Ele irá exemplificar com os desenvolvimentistas do MIT, pioneiros nessas atividades, desde a década de 1960. Himanen se apóia no defensor da cultura hacker, Eric Raymond, para explicar o espírito do trabalho do hacker, utilizando a palavra "paixão", o que Torwalds identificou como entretenimento. Himanen adéqua as palavras paixão e entretenimento, visando traduzir este espírito: "[...] la dedicación a una actividad que es, en esencia, interesante, fuente de inspiración y dicha". (HIMANEN, 2003, p.15-16).

O autor irá apontar que características semelhantes podem ser observadas com professores pesquisadores, artistas, "profissionais da informação", pessoas que trabalham com os meios de comunicação, editorial e desenho. Se considerado neste nível, as atitudes do homem apaixonado por sua atividade, pelo seu trabalho, os hackers são um exemplo emblemático de ética do trabalho, "[...] afianzada día a día, en la sociedad red, en la cual el papel de los profesionales de la información se halla en expansión."(16.). Este é um ponto que, segundo o autor, põe em xeque a Ética protestante e o espírito do capitalismo, que vem influenciando os meios de produção e nossas vidas desde seu entendimento em 1904.

Himanen identificou que a principal diferença da ética hacker do trabalho e a ética protestante do trabalho é que a primeira surge no âmbito científico acadêmico e a segunda nos monastérios. Porém, a partir de suas análises, o autor percebeu algumas semelhanças que o fizeram atribuir o título deste livro.

A essência da ética protestante weberiana coloca o trabalho elevado a uma condição poderosa, onde não é possível questionamentos diante sua atividade, sendo esta a mais importante da vida humana. Em contraponto, a natureza radical dos hackers propõe um "espírito alternativo", mais de acordo com a atual sociedade 
em rede, questionando a ética protestante a tanto tempo enraizada em nossas vidas.

Contudo, "tempo é dinheiro". Essa é uma máxima do capitalismo, que associa o trabalho a categoria tempo e que impregna a ética protestante. Uma consequência desse aspecto para os dias atuais é a necessidade de otimização do tempo. Em contraponto a perspectiva protestante de otimizar o tempo centrada no trabalho, Himanen observa uma tendência a flexibilização do tempo, visando o desenvolvimento de atividades que atribuem significado a atividade desenvolvida na sociedade em rede.

A criatividade também é um aspecto observado, passando a ser um elemento relevante nas relações do trabalho na perspectiva da ética hacker. Himanen termina este capítulo colocando que o trabalho é uma ação das atividades da vida, não sendo a principal. O mais importante é se respeitar enquanto seres humanos, considerando sua liberdade para desenvolver suas ações, vivendo de forma plena.

$\mathrm{Na}$ segunda parte de sua obra, Himanen continua fazendo paralelos e contrapontos para falar da ética do dinheiro. E inicia dizendo que "a nova economia não rompe com a antiga meta de ganhar dinheiro" e que embora o trabalho esteja subordinado ao dinheiro, ele ganha característica de autonomia.

Antagonismos observados com base no contraponto "ética protestante $\mathrm{x}$ ética hacker". De um lado forças da nova economia lutam por manter forte a posição do dinheiro, reforçando a ideia de propriedade e segurança das informações, resquícios do espírito protestante do capitalismo. Do outro lado, presenciamos um movimento de difusão dos resultados das atividades e das informações, uma cultura de liberdade quanto à disponibilização, disseminação e acesso à informação. 
Figura 1: Influências da ética protestante e da ética hacker quanto à informação nos dias atuais.

\section{Organização na Nova Economia: a informação}
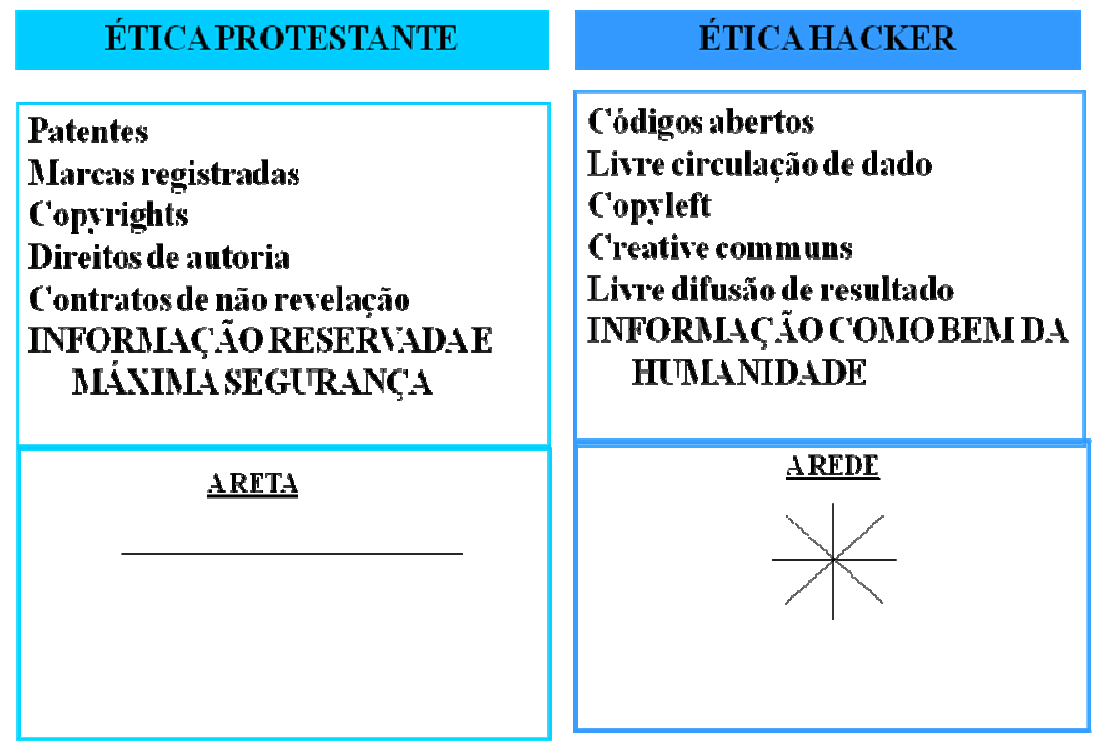

Fonte: Elaboração própria - resultado da nossa compreensão.

Ainda nesta segunda parte do livro, Himanen falará da motivação com base no dinheiro, procurando descrever os hackers capitalistas. No capítulo 4 compara a academia e o monastério, falando do modelo aberto e do modelo hacker de aprendizagem denominando de "academia rede". Conclui o capitulo com apresentação do modelo social, onde a internet é compreendida como um "meio efetivo para unir forças e, posteriormente, expandir e desenvolver."

Mas se trata de netiqueta ou ética da rede?. Assim Himanen anuncia a terceira parte do livro. Percebemos que é muito comum as pessoas confundirem netiqueta com a nética e até mesmo com a cibercidadania. Desse modo, o capítulo "A nética ou ética da rede" é esclarecedor, pois fala de aspectos como a consciência social dos hackers, a liberdade de expressão e a privacidade. Ainda nesta parte, Himanen apresenta como exemplo a crise que ocorreu em 1999 em Kosovo para falar de censura e liberdade de expressão. O caso abordado pelo autor é enriquecido com mensagens trocadas entre os cidadãos em meio a guerra e o restante do mundo, como também o comportamento e atuação de haskers e crackers no conflito. O autor segue falando do conceito de omniscência na perspectiva eletrônica, da realidade virtual e do espírito do capitalismo.

O autor conclui o livro apontando os sete valores da ética hacker (paixão, liberdade, sua atitude em relação à rede ou nética, atividade, preocupação 
responsável, liberdade de expressão e criatividade). Contudo ele alerta que poucos hacker compartilham destes valores. Himanen em seguida informa o quando foi significante entender a Genesis protestante para elaboração da ética do trabalho hacker.

A obra se encerra com quem a abriu. Somos brindados com um Epílogo "Informação e sociedade em rede" escrito por Castells, abordando a importância das contribuições e dos valores dos hackers, a exemplo de criatividade e inovações tecnológicas e de cunho cultural para a sociedade da informação. O livro ainda conta com uma "breve história do hackerismo em informática" no Apêndice.

\section{BLOCO DA COMPREENSÃO DO TEXTO}

"O homem é um sucesso se pula da cama de manhã e vai dormir à noite, e nesse meio tempo faz o que gosta."

(Bob Dylan, New York Times, 1989).

O texto em questão é compreensível e contribui para aqueles que, de alguma forma, precisam ter alguma noção de cultura hacker, ética hacker, diferença entre hackers e crackers e os valores desse movimento para a sociedade da informação. Constitui uma ótima referência, trazendo os principais conceitos. Contudo o texto apresenta posicionamento ideológico, deixando visível a pertença do autor quanto aos lados abordados na sua exposição. O leitor percebe que ele cumpre o que se propõe ao chegar na conclusão, pois é perceptível o fio condutor da ética protestante $\mathrm{X}$ ética hacker em todo o texto.

O livro de Himanen constitui um material para subsidiar e ampliar os debates sobre trabalho, dinheiro e educação (novas formas de aprendizagem) na sociedade da informação.

Sem dúvida a maior contribuição aparece nas discussões ligadas ao trabalho, corroborando com novas perspectivas frente ao modelo do espírito capitalista. Destaque para a riqueza de detalhes no contraponto com a obra weberiana. Himanen trabalha intensamente com a ideia de procurar compreender como os hackers trabalham. Os valores que norteiam a origem do software livre são os mesmos que fundamentam a ética e o trabalho hacker. Trata-se de uma lógica em torno do trabalho colaborativo, em torno de uma perspectiva generosa de compartilhamento, onde é característica fundamental daqueles que programam os 
Informação, trabalho e dinheiro: a felicidade está em se fazer o que se gosta.

computadores se desenvolver em uma ética centrada nos princípios do software livre. Ou seja, o princípio da colaboração, da generosidade e da liberdade.

Quanto ao aspecto dinheiro o autor avança para além das discussões capitalismo versus socialismo. Não se trata de defender um ou outro, mas sim compreender formas de se organizar politicamente, observando sua vocação no trabalho, considerando as novas formas de organização da sociedade contemporânea. Porém, isso não significa dizer que não existe dinheiro no universo hacker. Enquanto que na ética protestante o valor do dinheiro está associado, na maioria das vezes a atividades burocráticas, na ética hacker, os hackers evitam o monopólio e o manejo da informação em sistemas fechados por propriedade intelectual. Além desses aspectos, foi possível chegar a seguinte compreensão com respeito à relação do hacker com o dinheiro:

1. Trabalho não é sinônimo de dinheiro, contrariamente a máxima de Weber "o maior bem é ganhar mais dinheiro"; na ética hacker trabalho e dinheiro não são objetivos. Segundo Pekka Himanen, o trabalho é um valor autônomo mesmo que ainda subordinado ao dinheiro.

2. O compartilhamento de informações é um bem positivo e poderoso. Eis aqui um dos pontos que contrapõe ao mosteiro (São Beneditino); a ética hacker preza a liberdade de informações, tendo como precedente histórico a academia.

3. Dinheiro é UM motivo, mas não a força motriz. O consumo em todas as suas variáveis não ficou restrito ao período industrial. A nova economia apresenta um alto nível de capitalismo, paralelo a isso, é possível perceber que, na ética hacker, vemos um movimento contrário a isso, onde as invenções e informações são disponibilizadas aos terceiros.

4. Para os hackers o reconhecimento é mais importante que o dinheiro; contudo este reconhecimento individual não deve substituir a paixão. Esse reconhecimento deve resultar da "gana", diferente do protestantismo. O trabalho dos hackers, prezando mais os vínculos sociais e a paixão pela ação se constitui um modelo poderoso.

5. O fato de não colocar o dinheiro como objetivo principal não diminui o sucesso do modelo hacker. $O$ fato de se fazer o que realmente se gosta, o que dá PAIXÃO, é o que garante o sucesso. Isso me lembra a Força da vocação, de Joaci Góes, onde é lugar comum: "a felicidade é o objetivo final do ser humano". Unindo essas leituras percebi que associar outros valores quando a ideia fixa de ganhar dinheiro já está instalada nas pessoas, na organização e nos povos é muito mais difícil que tornar um interesse pessoal financeiramente viável ou mesmo rentável. Os hackers alcançam êxito porque 
se sentem como peixe dentro d'água em suas atividades de programadores apaixonados. Ainda lembrando de Góes: Por isso aproveitam os dias de repouso para mergulharem ainda mais e se aperfeiçoarem, sem preocupação em defender interesses materiais acima de suas necessidades. Essa é a realidade inspiradora dos grandes artistas, cientistas, etc. Isso está na contramão da ética protestante, onde os sujeitos anseiam pela sexta-feira para se livrarem do seu martírio.

6. Os hackers não são ingênuos com relação a dinheiro, capitalismo e globalização. Embora compreenda que trabalhando para terceiros não fundamente sua ação em paixão pessoal, o hacker pode trabalhar nesse ritmo, temporariamente, até alcançar independência financeira.

A figura a seguir ilustra a compreensão desses pontos comparando as duas éticas com relação às necessidades e às motivações. Na ética protestante a diversão é a motivação, está no topo, poucos têm acesso, pois é necessário garantir a sobrevivência e o labor é compreendido como o principal meio para alcançar tal rêve ou désire. Trabalho e diversão devem estar bem separados. Na ética hacker os valores também estão presentes, mas invertidos. A sobrevivência também está na base, tendo que ser superada para dar vazão a outras necessidades, que são mais intensas e que motivam o trabalho hacker.

Figura 2: Comparação da motivação e personalidade com relação ao trabalho e ao dinheiro

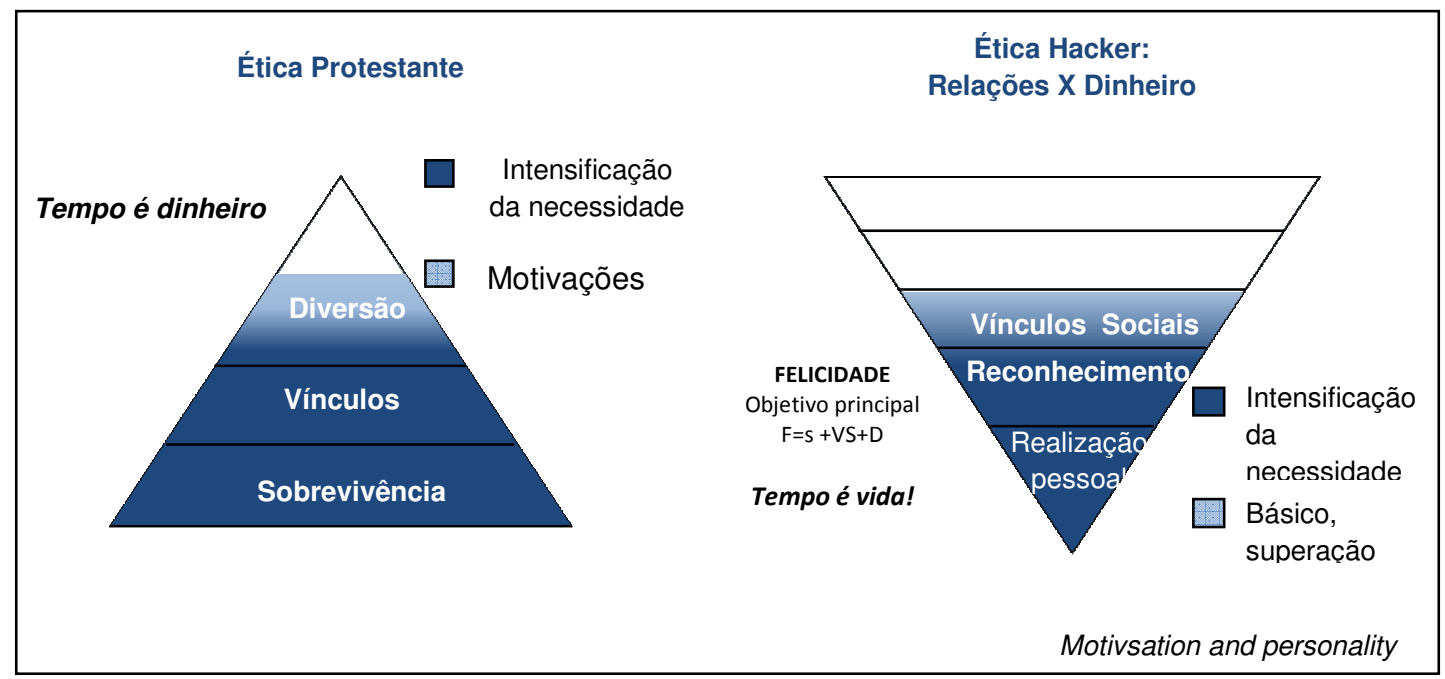

Fonte: Elaboração própria - resultado da nossa compreensão.

Com relação ao aspecto educação, percebemos que Himanen sinaliza que o compromisso ético do hacker entende a internet como bem comum e livre para toda civilização. Outro ponto que vale chamar atenção é a importância do erro; Aspecto 
Informação, trabalho e dinheiro: a felicidade está em se fazer o que se gosta.

que é transposto da relação do hacker com o desenvolvimento na informática, onde é possível se aprender com o erro, ou ainda explorá-lo de maneira coletiva, visando encontrar possíveis soluções.

$\mathrm{Na}$ nossa perspectiva julgamos que seja mais importante situar esta obra no seu tempo do que no seu espaço. Himanen escreveu e publicou este livro em 2001 nos Estados Unidos e, embora que suas ideias sejam influenciadas por suas experiências no MIT, o período é uma categoria relevante para entender o posicionamento do autor. Desse modo, a obra deve ser consumida criticamente, sempre com o aporte de outros referenciais mais contemporâneos sobre cultura hacker.

Recebido em: 01.07.2013

Aceito em: 18.03.2015 